\title{
DESIGN OF VACUUM CHAMBERS DOWNSTREAM OF NSLS X-RAY RING INSERTION DEVICES*
}

\author{
J. C. Schuchman, S. Sharma \\ National Synchrotron Light Source \\ Brookhaven National Laboratory, Upton, New York, USA
}

\section{Introduction}

In an electron storage ring the maximum power deposited in the vacuum chamber walls is that produced by the electron beam as it is accelerated through the bending magnets. In the NSLS X-ray ring this power is 58 watts per linear $\mathrm{cm}$ of arc chamber length, or $2 \mathrm{kw} / \mathrm{cm}^{2}$ taking into account the beam size. Standard water cooling techniques are adequate to protect the chambers from overheating under this range of power density. However, with the installation of wigglers and undulators, cooling of the chambers is no longer a trivial matter. Without proper interlocks and cooling, beams from these insertion devices can easily do permanent thermal damage to the chamber walls.

As part of the NSLS Phase II project three insertion devices are planned for the beamlines $X-1, X-17$ and $X-25$, namely, a soft $X$-ray undulator, a superconducting wiggler and a hybrid wiggler. Table 1 lists their characteristic parameters and power output. The effect of these insertion devices on the design of vacuum chambers downstream of these devices is the subject of this paper.

\section{Beam Deviations}

Under normal operation the electron beam in the storage ring experiences relatively small deviations (betatron oscillations) which do not result in exposure of the unprotected chamber surfaces to the insertion device radiations. However, in some accidental conditions, such as a trim magnet failure, single or multiple-turn short circuit of quadrupole magnets and internal shorts in the superconducting wiggler, the electron beam may be subjected to large deviations limited only by the horizontal and vertical acceptances of the ring. Maximum electron beam deviations at the center of the insertion devices where the betatron functions have their minimum values, are given [1] by:

- Maximum Displacements

- Horizontal, $x_{\max }= \pm 13 \mathrm{~mm}$

- Vertical, $y_{\max }= \pm 2.5 \mathrm{~mm}$

- Maximum Angular Deviations

- Horizontal, $x_{\max }^{\prime}= \pm 8$ mrad

- Vertical, $y_{\max }^{\prime}= \pm 8 \mathrm{mrad}$

* Work performed under the auspices of U.S. Department of Energy, under Contract No. DC-ACO2-76CH00016.

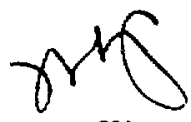


These values include the effect of various uncertainties regarding the dimensional and placement tolerances of the chambers, field errors and beta function values.

The envelope of all possible beam deviations at the center of insertion devices, $x$ and $x^{\prime}$ in the horizontal phase space, for instance, is given by the equation (see Ref. 2 ):

$$
\left(\frac{x}{x_{\max }}\right)^{2}+\left(\frac{x^{\prime}}{x_{\max }^{\prime}}\right)^{2}=1
$$

which represents a circle in $\left(\frac{x}{x_{\max }}, \frac{z^{\prime}}{x_{\max }^{\prime}}\right)$ coordinates. Vertical beam deviations satisfy a similar equation in $\left(\frac{y}{y_{\max }}, \frac{y^{\prime}}{y_{\max }^{\prime}}\right)$ coordinates.

The maximum extent of chamber exposure to the photon beam is determined by adding the above electron beam deviations to the opening angles of the radiation fan (Table 1). Calculations show that the roof and floor of both the straight section and the arc chamber (see Figure 1) can intercept the photon beam. Vertical walls of the straight section and an inner wall of the arc chamber would be exposed to the photon beam regardless of the horizontal radiation fan of the insertion device. Additionally, the roof and floor of the zero degree port, as designed originally with a $23 \mathrm{~mm}$ beam aperture, would have been illuminated under vertical beam deviations. In the following section we discuss various measures that have been taken to protect these chamber components from accidental exposure.

Table 1. X-ray Insertion Devices (2.5 GeV, $250 \mathrm{ma})$

\begin{tabular}{|c|c|c|c|}
\hline Parameters & $\begin{array}{c}\text { Soft X-ray } \\
\text { Undulator }(X-1)\end{array}$ & Superconduct. & Hybrid \\
\hline Magnetic Field, $B_{\max }(T)$ & 0.35 & 5.0 and & 1.1 \\
\hline & & 2.5 (endpoles) & \\
\hline Number of Periods, $\mathbf{N}$ & 37 & $\begin{array}{c}2.5(5.0 T) \\
1(2.5 T)\end{array}$ & 15 \\
\hline Period Length, $\lambda(\mathrm{cm})$ & 8.0 & 17.4 & 12.0 \\
\hline Characteristic Energy, $\epsilon_{c}(\overline{K e V})$ & & $\begin{array}{l}20.28(5.0 T) \\
10.39(2.5 T)\end{array}$ & 4.57 \\
\hline Hz. Opening Angle, $2 \theta_{\text {max }}$ (mrad) & 1.31 & 33.3 & 5.0 \\
\hline Vert. Opening Angle, $2 / \gamma($ mrad $)$ & 0.409 & 0.409 & 0.409 \\
\hline Total Power, $(k w)$ & 0.36 & 11.83 & 2.16 \\
\hline Power $/$ mrad $\theta,(k w / m r a d)$ & $0.3 \overline{2}$ & 0.50 & $0 . \overline{54}$ \\
\hline Power Density, $\left.\left(k w / m_{r a d}\right)^{2}\right)$ & 1.15 & 1.59 & 1.73 \\
\hline
\end{tabular}

\section{Straight Section}

Several design modifications have been made to the original straight sections in order to protect them against large horizontal and vertical beam deviations. Originally the straight sections had extruded water channels only on the outside walls. Cooling channels on the inside wall were later added to the superconducting wiggler's straight section because of its wide radiation fan. The inside cooling channels 
have now been provided to the other two straight sections as well. In addition, a water-cooled horizontal radiation shield (Figure 1) has been added immediately upstream of the arc chamber to shadow some of its surfaces that could be exposed to the beam.

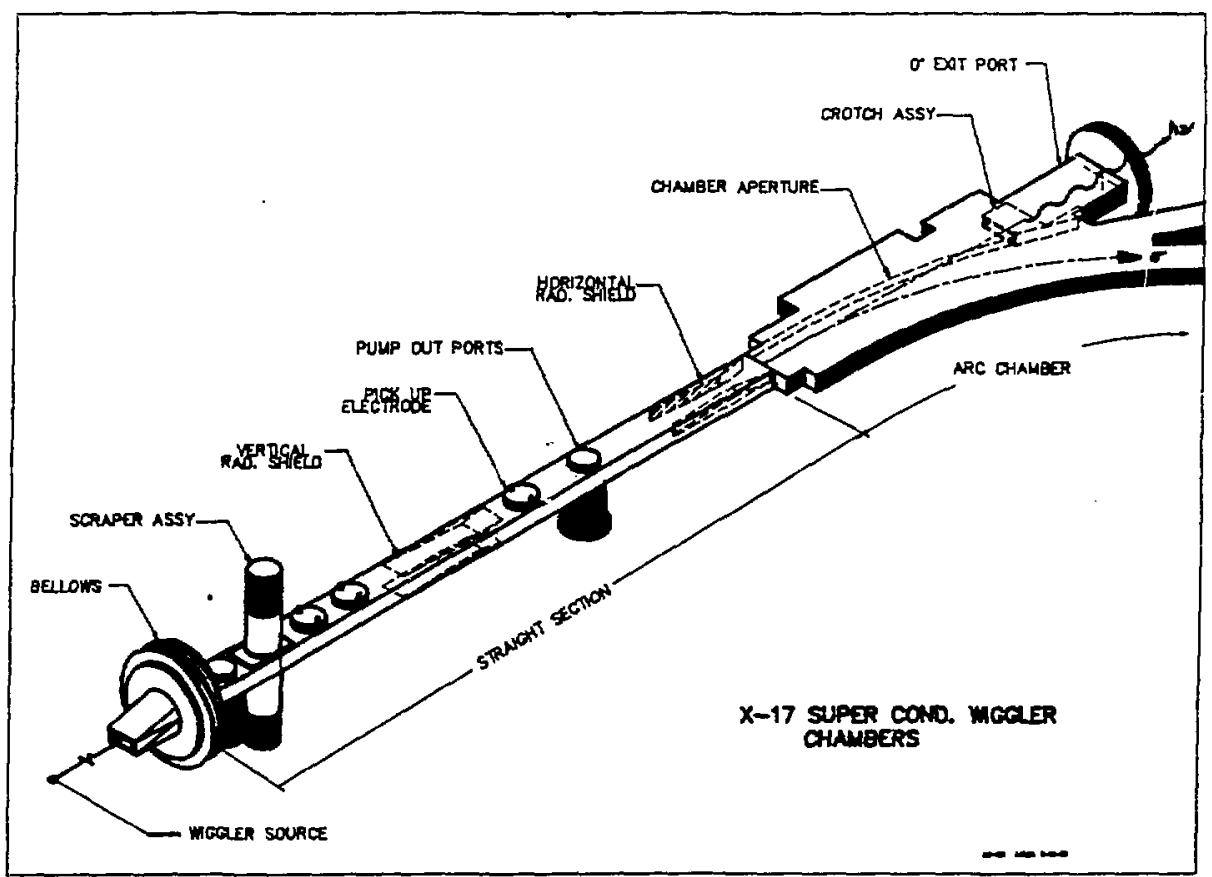

Figure 1. Typical Chamber Downstream of an Insertion Device

Water-cooling of the straight section's roof and floor, which can overheat under vertical beam deviations, was found to be quite difficult. This is due to the following two reasons: (1) space limitations between the quadrupole magnet gaps do not leave enough room for adding water channels, and (2) several cutouts in the roof and floor for pumpout ports and pick-up electrodes expose local surfaces to the beam at normal incidence resulting in extremely high power densities.

A combination of passive and active schemes have been adopted to protect the roof and floor. The passive scheme consists of a water-cooled vertical radiation shield and an electron beam scraper located at positions shown in Figure 1. The vertical radiation shield shadows the normal incidence cutout surfaces, whereas the beam scraper shadows all of the roof and floor by lowering a pair of blades into the bearn [3]. No scraper is provided for the soft $\mathrm{X}$-ray undulator because 
of its relatively low power output which does not cause overheating of the roof and floor. Furthermore, the scrapers are not engaged during the injection phase when the beam deviations are larger and any restriction of the vertical aperture is undesirable. The beam power during injection is, therefore, required to be sufficiently low so that the chambers are safe even without the scraper protection.

In the active protection scheme, vertical electron beam deviations would be monitored using a set of pick-up electrodes. The beam would be dumped by triggering an $\mathrm{RF}$ interlock when the deviations become unacceptably large. For added protection, interlocking the $R F$ system with a vacuum gage in the arc chamber and a photon beam position monitor in the front end of the beamline is also being considered. As with the beam scraper, the active protection scheme is not necessary for the soft X-ray undulator.

\section{Arc Chamber}

The arc chamber, which was originally made from an aluminum extrusion, has been extensively modified. The most drastic modification is the replacement of one half of the curved section with a new piece of chamber made from machined plates that have been welded along the periphery. This major change produced a flat uniform chamber with well defined crotch and exit port locations. The machining approach resulted in tolerances of less than $0.5 \mathrm{~mm}$ in flatness, twist and position, which were unattainable using the original welded extrusion approach.
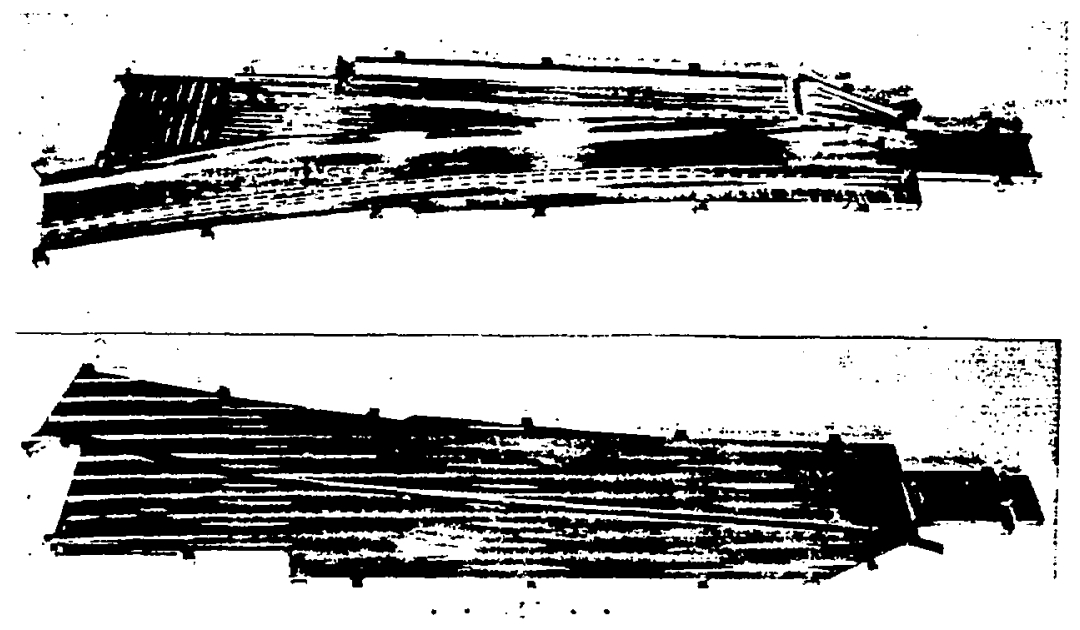

Figure 2a. Top, Machined Plate, Vacuum Side

2b. Bottom, Machined Plate, Outside Surface

Figures $2 \mathrm{a}$ and $2 \mathrm{~b}$ show both sides of one machined plate. After machining the plates were welded along the outside edge using both electron-beam (e-b) 
and TIG welding techniques. The channel shown in Figure $2 \mathrm{~b}$ was machined and subsequently covered by a thin strip by e-b welding. This channel cools the inside surface of the beam slot through which the radiations exit to the zero degree port. The thin strip was welded off-center relative to the channel so that the weld heat-affected zone would be away from the critical shoulder region, see Figure 3. This was confirmed by tests on weld samples which showed no change in Rockwell hardness in the shoulder region.

The beam slot height was reduces from $23 \mathrm{~mm}$ to $15 \mathrm{~mm}$ in order to shadow the roof and floor of the zero degree exit port. For additional protection the exit port was modified to include water cooling on top, bottom, and inside surfaces. In all three cases grooves were machined in the chamber port which were subsequently closed by e-b welds to form water channels.

An aluminum alloy, 2219-T87, was selected as the plate material because of its high yield strength at elevated temperatures. A pre-installation vacuum bakeout of the chamber at $170^{\circ} \mathrm{C}$ served a dual purpose. It provided a bakeout and post-weld heat treatment temperature at the same time. There was no noticeable change in the chamber dimension or shape after the bakeout. No problems were encountered when welding alloy 2219 to itseif or to other parts of the chamber made of alloy 6061. Welding rods of alloy 2319 were used when joining 2219 to itself, whereas alloy 4043 rods were used when welding 2219 to 6061 .

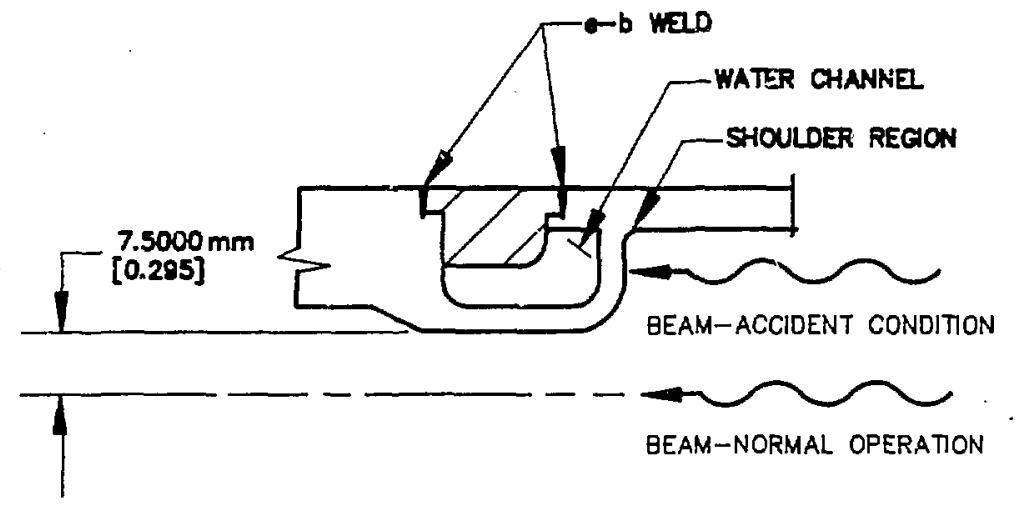

Figure 3. Arc Chamber Beam Slot and Cooling Channel

\section{Analysis Results}

Detailed finite element analyses for the modified vacuum chambers were carried out to ensure that they would maintain their structural integrity when subjected to the intense photon beams, and to ascertain that water boiling would not occur in the cooling channels. A general purpose finite element program, ANSYS [4], was used for all analyses. Film coefficients for the convective heat transfer were 
calculated based on a water flow rate of 7.7 GP.M in one loop comprising the arc chamber cooling channel and the horizontal radiation shield, and 3.2 GPM in another loop comprising the remaining chamber sections. A summary of the analysis results is given below for the following critical chamber components: (i) vertical walls of the straight section, (ii) horizontal radiation shield, (iii) vertical radiation shield, and (iv) arc chamber.

(i) Vertical Walls of the Straight Section - A maximum incident power of 58.3 watts $/ \mathrm{cm}$ is intercepted by the straight section vertical walls at $1.76 \mathrm{~m}$ downstream of the superconducting wiggler. The beam incidence angle is $20.9 \mathrm{mrad}$ which includes both the beam deviation and the horizontal fan. Heat transfer calculations show a maximum temperature rise of $49.7^{\circ} \mathrm{C}$ at the aluminum surface and a temperature drop of $16^{\circ} \mathrm{C}$ across the water film. The resulting peak thermal stress is $12 \mathrm{ksi}$. In comparison, the yield strength of the aluminum alloy (6063-T5) at the above temperature is $20 \mathrm{ksi}$.

(ii) Horizontal Radiation Shield - The most critical exposure to this chamber component, which is located at $5.13 \mathrm{~m}$ from the source, occurs from the hybrid wiggler when the electron beam is deviated $8.0 \mathrm{mrad}$ horizontally and $2.5 \mathrm{mrad}$ vertically. The intercepted power density at an incidence angle of 34.1 mrad is 35.9 watts $/ \mathrm{cm}$ which results in a maximum temperature rise of $63.6^{\circ} \mathrm{C}$ in the aluminum channel. Temperature drop across the water film near the beam impact region is $39.4^{\circ} \mathrm{C}$. In this local region compressive thermal stresses develop because the shield is constrained at both ends. The maximum thermal stress of $10.4 \mathrm{ksi}$ is, however, only 28 percent of the yield sirength ( $37 \mathrm{ksi}$ ) of the aluminum alloy 5456-H116 used for the channel.

(iii) Vertical Radiation Shield - Because of the active and passive protection schemes provided for the superconducting and hybrid wiggler devices, the vertical radiation shield itself would be protected from their radiations at full beam power. Therefore, the maximum power density incident on this shield would come from the soft X-ray undulator. At a source distance of $3.95 \mathrm{~m}$ and incidence angle of $37.3 \mathrm{mrad}$, the intercepted power is 108.3 watts per linear $\mathrm{cm}$ of the shield length. This causes a maximum temperature rise of approximately $94.6{ }^{\circ} \mathrm{C}$, and a water film temperature drop of $18.1^{\circ} \mathrm{C}$. The shield is subjected to a maximum thermal stress of $14.7 \mathrm{ksi}$, which is considerably lower than the yield strength (38 $k s i)$ of the 6061-T6 aluminum alloy used for this component.

(iv) Arc Chamber - In the worst case of power loading, the hybrid wiggler beam strikes the shoulder region of the arc chamber cooling slot (Figure 3), at $6.14 \mathrm{~m}$ from the source and at $104.7 \mathrm{mrad}$ angle of incidence. The power absorbed is 92.0 watts $/ \mathrm{cm}$ resulting in a maximum temperature rise of $62.4{ }^{\circ} \mathrm{C}$. Maximum temperature drop across the water film is $32.9^{\circ} \mathrm{C}$. The shoulder region is basically constrained against thermal expansion because of the size and geometrical configuration of the arc chamber. Also, this region is subjected to significant atmospheric pressure stresses owing to the large unsupported span of the chamber plate. The maximum combined effective stress under thermal and pressure loads (including both atmospheric and water pressures) is calculated to be $20.6 \mathrm{ksi}$ which compares with $37 \mathrm{ksi}$ yield strength of the 2219-T87 alloy at 
elevated temperature.

\section{Conclusions}

Highly intense photon beams from the insertion devices can expose downstream vacuum chambers to severe thermal loads. At NSLS a combination of design modifications, improved fabrication techniques, and active and passive protection schemes, were implemented in order to protect the X-ray ring vacuum chambers. Detailed analyses, discussed in the paper, were carried out which confirmed the thermal and structural integrity of the modified chamber components.

\section{Acknowledgment}

The modified design of insertion device chambers is based on the hard work and diligent effort of many NSLS staff members who defined problems and proposed solutions. This paper is simply a reporting on the design approach that was undertaken,

\section{References}

1. B. Craft and G. Decker, Brookhaven National Laboratory, Private communication, August 1987.

2. G. K. Green, "Spectra and Optics of Synchrotron Light Source," in Proposal for National Synchrotron Light Source, Brookhaven National Laboratory, Upton, NY, BNL-50595 (1977)

3. R. Alforque and S. Sharma "Design of a Beam Scraper for Thermal Protection of the X-ray Vacuum Chamber," paper under preparation.

4. ANSYS - Swanson Analysis Systems Inc., Houston, PA

\section{DISCLAIMER}

This report was prepared as an account of work sponsored by an agency of the United States Government. Neither the United States Government nor any agency thereof, nor any of their employees, makes any warranty, express or implied, or assumes any legal liability or responsibility for the accuracy, completeness, or usefulness of any information, apparatus, product, or process disclosed, or represents that its use would not infringe privately owned rights. Reference herein to any specific commercial product, process, or service by trade name, trademark, manufacturer, or otherwise does not necessarily constitute or imply its endorsement, recommendation, or favoring by the United States Government or any agency thereof. The vicws and opinions of authors expressed herein do not necessarily state or reflect those of the United States Government or any agency thereof. 